\title{
Berberine regulates melanin synthesis by activating PI3K/AKT, ERK and GSK3 $\beta$ in B16F10 melanoma cells
}

\author{
YOUNG CHAN SONG ${ }^{1,3 *}$, YONGHEE LEE ${ }^{2 *}$, HYEONG MI KIM ${ }^{2}$, MOO YEOL HYUN ${ }^{2,3}$, \\ YUN YOUNG LIM ${ }^{2}$, KYE YONG SONG ${ }^{1,3}$ and BEOM JOON KIM ${ }^{2,3}$ \\ Departments of ${ }^{1}$ Pathology and ${ }^{2}$ Dermatology, Chung-Ang University College of Medicine; \\ ${ }^{3}$ Department of Medicine, The Graduate School, Chung-Ang University, Seoul, Republic of Korea
}

Received May 24, 2014; Accepted February 17, 2015

DOI: $10.3892 / \mathrm{ijmm} .2015 .2113$

\begin{abstract}
Berberine, an isoquinoline alkaloid, has a wide range of beneficial properties, including anti-bacterial, anti-inflammatory, anti-cancer, and cholesterol-lowering effects. Recently findings suggest that berberine improves glucose and lipid metabolism disorders. In the present study, we examined the mechanism underlying the inhibitory effect of berberine on $\alpha$-melanocyte-stimulating hormone ( $\alpha$-MSH)-stimulated B16F10 melanoma cells. The results showed that berberine attenuated $\alpha$-MSH induction of the microphthalmia-associated transcription factor (MITF) and tyrosinase in a dose-dependent manner. To elucidate the mechanism underlying the inhibitory effect of berberine, we examined the effect of $\alpha$-MSH-stimulated phosphorylation of PI3K/AKT, ERK, and GSK3 $\beta$. The results showed that treatment with berberine resulted in a reduction in the phosphorylation of PI3K/AKT, ERK, and GSK3 $\beta$. Taken together, the results suggested that berberine inhibits melanin synthesis and tyrosinase activity by downregulating the expression of MITF and tyrosinase. Thus, these findings may contribute to the potential application of berberine in the prevention and treatment of skin pigmentation disorders.
\end{abstract}

\section{Introduction}

Human skin color ranges from white to brown to black due to the presence of the pigment melanin, which is crucial in

Correspondence to: Beom Joon Kim, Department of Dermatology, Chung-Ang University College of Medicine, Seoul 137-701, Republic of Korea

E-mail: beomjoon@unitel.co.kr

*Contributed equally

Abbreviations: MITF, microphthalmia-associated transcription factor; $\alpha$-MSH, $\alpha$-melanocyte-stimulating hormone

Key words: B16F10 melanoma cells, melanin synthesis, tyrosinase, microphthalmia-associated transcription factor, phosphotidyl inositol 3-kinase/AKT, extracellular signal-regulated kinases, glycogen synthase kinase $3 \beta$ protecting the skin against ultraviolet (UV) light and other environmental challenges. Melanogenesis, a highly regulated process, is modified by transcriptional, translational, and post-translational mechanisms. Marked cellular and molecular connections among cell populations have been identified in the skin; however, the key players are fibroblasts, keratinocytes, and melanocytes (1). The excessive accumulation of melanin can lead to hyperpigmentation or even skin cancer $(2,3)$. Many inhibitors of melanin synthesis have been isolated from natural sources, including flavonoids, kojic acid, arbutin, and hydroquinone (4-9). Previous findings have shown that arbutin increases the pigmentation of cultured human melanocytes, while kojic acid has toxic and mutagenic effects when used for prolonged periods of time (10-12). Therefore, the safety and effectiveness of certain natural herbal extracts for skin pigmentation that have other properties including anti-cancer, anti-inflammatory, and anti-bacterial activity have been investigated. These well-known materials are polyphenol, curcumin, and rosemary (13-15).

Berberine, an isoquinoline alkaloid, is a common component of a variety of plant species, particularly in the Berberidaceae family. Although berberine has a wide range of pharmacological effects, including anti-bacterial, anti-inflammatory, anti-cancer and cholesterol-lowering effects (16-19), the precise mechanisms involved remain to be determined. In this study, we examined the inhibitory effect of berberine on $\alpha$-melanocyte stimulating hormone ( $\alpha$-MSH)-induced melanogenesis in B16F10 melanoma cells in addition to the underlying mechanism of action.

\section{Materials and methods}

Materials. Berberine chloride hydrate, mushroom tyrosinase, 3,4-dihydroxy-L-phenylalanine (L-DOPA), PD 98059 (ERK inhibitor), BIO (GSK3 $\beta$ ) and 3-(4,5-dimethylthiazol-2-yl)-2, 5-diphenyltetrazolium bromide (MTT) were purchased from Sigma-Aldrich Co. (St. Louis, MO, USA). LY 294002 (PI3K inhibitor) was purchased from Calbiochem (Darmstadt, Germany). Dulbecco's modified Eagle's medium (DMEM), fetal calf serum, trypsin EDTA, phosphate-buffered saline (PBS), and penicillin/streptomycin were purchased from Welgene, Inc. (Daegu, Korea). Antibodies specific to tyrosinase and $\beta$-actin were purchased from Santa 
Cruz Biotechnology, Inc. (USA). Antibodies specific to phospho-ERK1/2 (Thr202/Tyr204), phospho-AKT, GSK3 $\beta$ and $\beta$-catenin were from Cell Signaling Technology (Beverly, MA, USA).

Cell cultures. The B16F10 melanoma cells were purchased from ATCC (American Type Culture Collection; Manassas, VA, USA). The cells were maintained at $37^{\circ} \mathrm{C}$ in a humidified atmosphere of $95 \%$ air and $5 \% \mathrm{CO}_{2}$ in DMEM supplemented with $10 \%(\mathrm{v} / \mathrm{v})$ heat-inactivated fetal bovine serum, $100 \mathrm{U} / \mathrm{ml}$ penicillin and $10 \mu \mathrm{g} / \mathrm{ml}$ streptomycin.

Cell viability assay. A cell viability assay was determined using an MTT assay. Briefly, the cells were seeded at a desity of $2 \times 10^{5}$ cells/well in 6-well plates. Prior to treatment, the cells were cultured for $24 \mathrm{~h}$ in serum-free medium. Following treatment with the indicated concentrations of $0,0.01,0.1,1$ and $10 \mu \mathrm{g} / \mathrm{ml}$ berberine in each well, the cells were incubated for $24 \mathrm{~h}$. The supernatant was removed and MTT solution was added to each well prior to incubation for $4 \mathrm{~h}$. Subsequently, $1.5 \mathrm{ml}$ of dimethylsulfoxide (DMSO) was added to each well to solubilize any deposited formazon. Folowing incubation of $10 \mathrm{~min}$ at room temperature, optical density (OD) was determined at $540 \mathrm{~nm}$ on an ELISA plate reader (ThermoMax Microplate Reader; Molecular Devices, Sunnyvale, CA, USA). The percentage of viable cells in each well was calculated with respect to the OD value of living cells of the control group $(100 \%)$.

Measurement of melanin content. Cells $\left(2 \times 10^{5}\right.$ cells) were incubated in 6-well plates overnight. After $24 \mathrm{~h}$ incubation, $\alpha$-MSH $(1 \mu \mathrm{M})$ was added per well and treated with increasing concentrations of berberine $(0.01-10 \mu \mathrm{g} / \mathrm{ml})$ in phenol-red free DMEM for 3 days. Then, $200 \mu \mathrm{l}$ of medium were transferred in 96-well plates and the OD value was measured using an ELISA plate reader (VersaMax ELISA Microplate Reader; Molecular Devices) at $400 \mathrm{~nm}$. Cell numbers were then counted using a haemocytometer. Melanin productions were expressed as percentages of those of untreated controls.

Tyrosinase activity. Tyrosinase activity was assayed as DOPA oxidase activity. In order to measure tyrosinase activity in cells, B16F10 melanoma cells were seeded at a density of $1 \times 10^{5}$ cells in 6-well plates, and incubated in DMEM with berberine. After 3 days, the cells were washed with PBS and lysed with lysis buffer [0.1 M phosphate buffer ( $\mathrm{pH}$ 6.8) containing $1 \%$ Triton X-100]. The cells were then disrupted by freeze-thawing, and lysates were clarified by centrifugation at $21,000 \mathrm{x} \mathrm{g}$ for $20 \mathrm{~min}$. After quantifyingthe protein content using a protein assay kit (Bio-Rad, Hercules, CA, USA), the cell lysates were adjusted to the same amount of protein with a lysis buffer. Reaction mixtures consisting of protein, $10 \mathrm{mM}$ L-DOPA and $0.1 \mathrm{M}$ phosphate buffer were assayed in 96-well plates at $37^{\circ} \mathrm{C}$. Absorbance was measured every $10 \mathrm{~min}$ for at least $1 \mathrm{~h}$ at $475 \mathrm{~nm}$ using an ELISA reader followed by incubation at $37^{\circ} \mathrm{C}$. A cell-free assay system was used to investigate the direct tyrosinase effect of berberine. A reaction mixture consisting of $10 \mu \mathrm{g} / \mathrm{ml}$ mushroom tyrosinase and $10 \mathrm{mM}$ L-DOPA was assayed in 96 -well plates at $37^{\circ} \mathrm{C}$. After $30 \mathrm{~min}$, absorbance was measured as described above at $475 \mathrm{~nm}$.
Western blot analysis. Treated whole cell extracts were lysed in RIPA buffer containing $50 \mathrm{mM}$ Tris ( $\mathrm{pH}$ 7.4), $150 \mathrm{mM} \mathrm{NaCl}, 0.5 \%$ Triton X-100, $0.1 \%$ sodium dodecyl sulfate (SDS) (Sigma-Aldrich Co.) and a protease inhibitor cocktail tablet (Roche Diagnostics, Indianapolis, IN, USA) for preparation of the cell extracts. The protein concentration of the extracts was estimated with Bradford reagent (Bio-Rad) using bovine serum albumin (BSA) as the standard.

For western blot analysis, cell lysates containing $20 \mu \mathrm{g} / \mathrm{ml}$ of proteins were resolved on a $10 \%$ polyacrylamide gel. The separated proteins were then transferred onto a PVDF membrane (Immobilon; Millipore, Bedford, MA, USA). The membrane was saturated with $5 \%$ dried milk in tris-buffered saline containing $0.5 \%$ Tween-20. A western blot analysis was performed by first incubating the membrane in primary antibodies, such as MITF, Tyrosinase, p-AKT, t-AKT, p-ERK, t-ERK, p-GSK $3 \beta, \mathrm{t}$-GSK3 $\beta$ and $\beta$-antin overnight at $4^{\circ} \mathrm{C}$, followed by further incubation with horseradish peroxidase-conjugated secondary antibody (Vector Laboratories, Inc., Burlingame, CA, USA). The membrane developed in the enhanced chemiluminescence (ECL) Western detection reagents (Amersham Pharmacia Biotech, Piscataway, NJ, USA).

Quantitative RT-PCR. Total RNA was extracted using the TRIzol reagent (Invitrogen, Carlsbad, CA, USA) according to the manufacturer's instructions after treatment and quantified by an ND1000 spectrophotometer (Thermo Fisher Scientific, Wilmington, DE, USA) at an absorbance of $260 \mathrm{~nm}$. cDNA was synthesized with $2 \mu \mathrm{g}$ of denatured total RNA in a final volume of $20 \mu \mathrm{l}$ of buffer containing $\mathrm{MgCl}_{2}, \mathrm{KCl}$, dNTPs, and oligo-dT reverse transcriptase by incubation at $42^{\circ} \mathrm{C}$ for $60 \mathrm{~min}$. The cDNA obtained was amplified with the following primers: microphthalmia-associated transcription factor (MITF) forward, 5'-CGCCTGATCTGGTGAATCG-3' and reverse, 5'-CCTGGCTGCAGTTCTCAAGAA-3'; tyrosinase forward, 5'-TTGCCACTTCATGTCATCATAGAAT ATT-3' and reverse, 5'-TTTATCAAAGGTGACTGCTATACA AAT-3'; and GAPDH forward, 5'-CGTCCCGTAGACAA AATGGT-3' and reverse, 5'-TTGATGGCAACAATCTC CAC-3'. Quantitative PCR was performed with a C1000 Touch $^{\mathrm{TM}}$ ThermalCycler(Bio-Rad) using SYBR-Green(Takara, Shiga, Japan). Reactive mixtures were incubated for 40 cycles at $95^{\circ} \mathrm{C}$ for $15 \mathrm{sec} ; 58^{\circ} \mathrm{C}$ for $45 \mathrm{sec}$ and $72^{\circ} \mathrm{C}$ for $20 \mathrm{sec}$. Gene expression was normalized to those of the housekeeping gene encoding GAPDH.

Immunocytochemistry. B16F10 melanoma cells were seeded in two-chamber slides. After incubation for $24 \mathrm{~h}$, immunocytochemistry (ICC) was performed. The slides were fixed with $4 \%$ paraformaldehyde for $30 \mathrm{~min}$ at room temperature. After washing with DPBS, the cells were permeabilized with $0.05-0.1 \%$ Triton X-100 in PBS or TBST for 10-15 min at room temperature and then blocked with 5\% BSA in 0.05\% Triton X-100 for $30 \mathrm{~min}$ at room temperature. The slides were incubated with tyrosinase and MITF antibodies at $4^{\circ} \mathrm{C}$ for overnight. After washing, the slides were incubated with fluorescein isothiocyanate (FITC)-conjugated secondary antibody (Santa Cruz Biotechnology, Inc., Santa Cruz, CA, USA). These slides were mounted using fluorescent mounting medium with 4',6-diamidino-2-phenylindole (DAPI) (Golden Bridge 

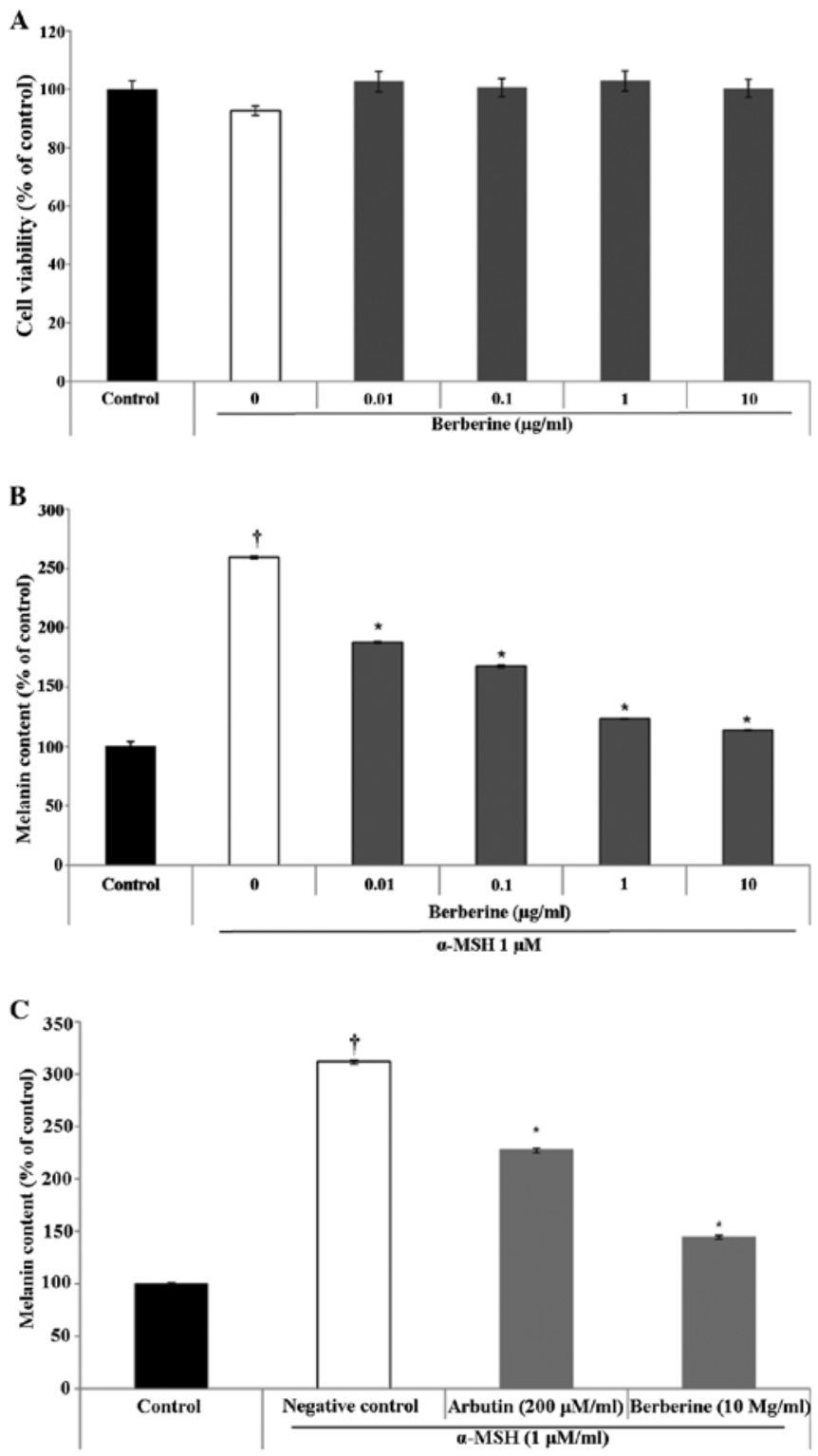

Figure 1. Effect of viability and melanin contents by berberine in B16F10 melanoma cells. (A) After B16F10 melanoma cells were incubated for $24 \mathrm{~h}$ in 96-well plates, the cells were treated with various concentrations of berberine $(0,0.01,0.1,1$ and $10 \mu \mathrm{g} / \mathrm{ml})$ for $24 \mathrm{~h}$. Cell viability was determined using 3-(4,5-dimethylthiazol-2-yl)-2,5-diphenyltetrazolium bromide (MTT) assay. (B and C) After cells were incubated for $24 \mathrm{~h}$ in 6-well plates, the cells were co-treated with various concentrations of berberine and $\alpha$-melanocyte-stimulating hormone $(\alpha-\mathrm{MSH})(1 \mu \mathrm{M} / \mathrm{ml})$ for $72 \mathrm{~h}$. Arbutin $(200 \mu \mathrm{M} / \mathrm{ml})$ was used as a positive control. Melanin contents by berberine were largely decreased in a dose-dependent manner in the MSH-stimulated B16F10 melanoma cells. Results are expressed as a percentage of viability and melanin contents compared to the control. Data are expressed as the mean $\pm \mathrm{SD}(\mathrm{n}=3)$. ${ }^{\dagger} \mathrm{P}<0.05$ vs. control, " $<<0.05$ vs. $\alpha$-MSH-stimulated.

International, Inc., Mukilteo, WA, USA) and observed by fluorescence microscopy (Olympus IX71; Olympus, Tokyo, Japan).

Statistical analysis. Statistical analyses were performed using SPSS version 18.0 for Windows (SPSS Inc., Chicago, IL, USA). Results are expressed as the means \pm SD. Data were analyzed by one-way ANOVA followed by a Duncan's test for multiple comparisons. A two-tailed value of $\mathrm{p}<0.05$ was considered statistically significant.

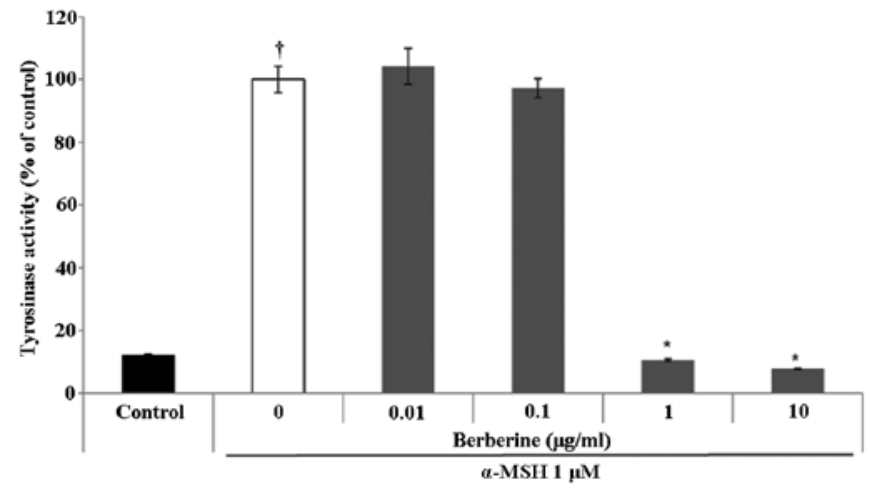

Figure 2. Effect of tyrosinase activity by berberine in B16F10 melanoma cells. After cells were incubated for $24 \mathrm{~h}$ in 6 -well plates, the cells were co-treated with various concentrations of berberine $(0,0.01,0.1,1$ and $10 \mu \mathrm{g} / \mathrm{ml})$ and $\alpha$-melanocyte-stimulating hormone ( $\alpha$-MSH) $(1 \mu \mathrm{M})$ for $72 \mathrm{~h}$. The tyrosinase activity of the berberine-treated cells was measured. Each determination was made in triplicate, and the data shown are the mean \pm SD. $\mathrm{P}<0.05$ vs. control, ${ }^{*} \mathrm{p}<0.05$ vs. $\alpha$-MSH-stimulated.

\section{Results}

Effect of viability and melanin contents by berberine in B16F10 melanoma cells. After examining the effects of berberine on cell viability, we examined the effects of berberine on the melanin content. As the berberine did not decrease the viability of cells up to a concentration of $10 \mu \mathrm{g} / \mathrm{ml}$ (Fig. 1A), this concentration was used in subsequent experiments. We quantified the melanin content and observed that even $10 \mu \mathrm{g} / \mathrm{ml}$ of berberine inhibited melanin production significantly. At concentrations of $10 \mu \mathrm{g} / \mathrm{ml}$, cells were still viable, and the cellular melanin content decreased to 2.3-fold (Fig. 1B). In addition, the inhibitory effect for melanin contents by berberine $(10 \mu \mathrm{g} / \mathrm{ml})$ was more effective compared to that of arbutin $(200 \mu \mathrm{M} / \mathrm{ml})$, which is known to inhibit tyrosinase activity (Fig. 1C).

Effect of tyrosinase activity by berberine in B16F10 melanoma cells. Many inhibitors of melanin synthesis induce inhibition of tyrosinase directly. Thus, to investigate the direct effects of berberine on tyrosinase, we measured the tyrosinase activity of mushroom tyrosinase in a cell system and a cell-free system. In the cell system, tyrosinase activity was significantly decreased by berberine at concentrations ranging from 1 to $10 \mu \mathrm{g} / \mathrm{ml}$ (Fig. 2), whereas berberine was found to have no direct inhibitory effect in the cell-free system (data not shown).

Effect of berberine MITF and tyrosinase levels on B16F10 melanoma cells. To elucidate the mechanism of melanogenesis, including the expression of tyrosinase and MITF, underlying the effect of berberine, B16F10 cells were treated with the extract prior to stimulation with $\alpha$-MSH for 24, 48 and $72 \mathrm{~h}$. qPCR and western blot analysis were conducted to analyze the resulting cell lysates. Fig. 3A shows that the $\alpha$-MSH-stimulated expression of MITF and tyrosinase mRNA was suppressed by berberine $(10 \mu \mathrm{g} / \mathrm{ml})$ treatment. Furthermore, as shown in Fig. 3B, $10 \mu \mathrm{g} / \mathrm{ml}$ of berberine decreased the $\alpha$-MSH-stimulated protein expression of tyrosinase and MITF. The decreased protein level of tyrosinase was confirmed by ICC (Fig. 3C). 
A

口MITF

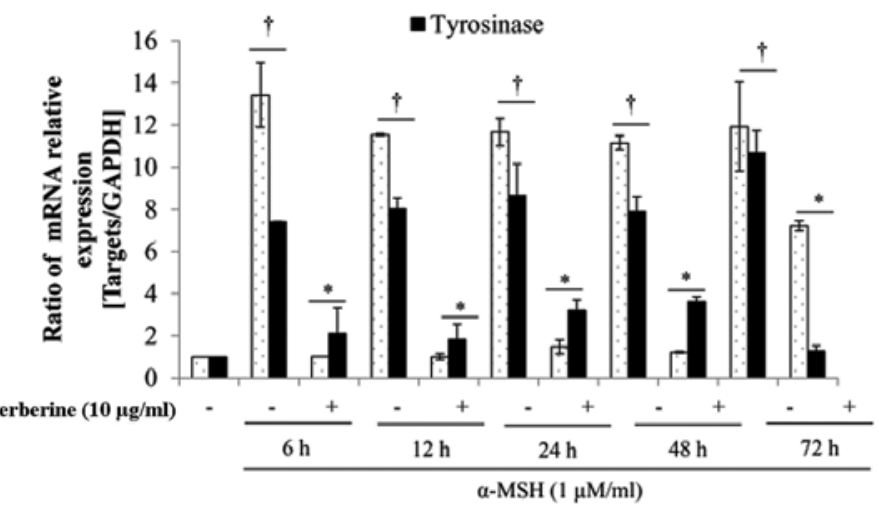

B

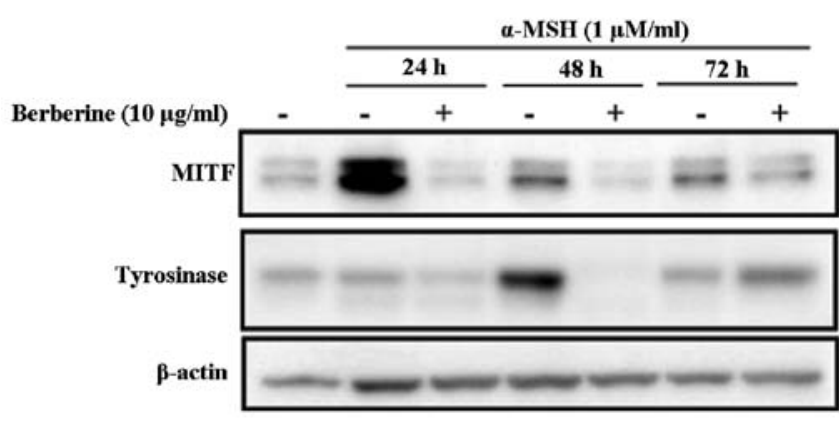

$\mathbf{C}$

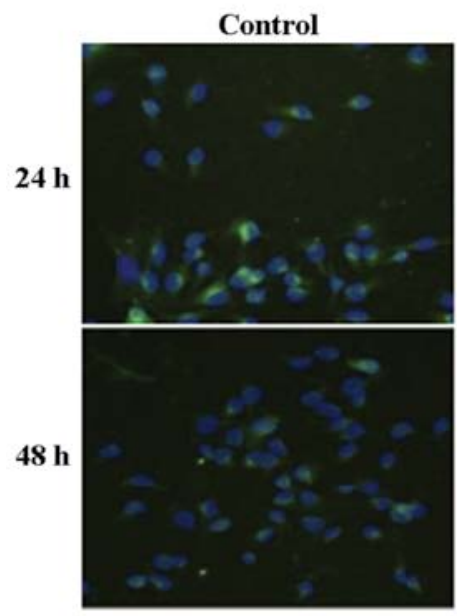
$\alpha-\mathrm{MSH}(1 \mu \mathrm{M} / \mathrm{ml})$ $\alpha-\mathrm{MSH}$
+ Berberine $(10 \mu \mathrm{Mg} / \mathrm{ml})$
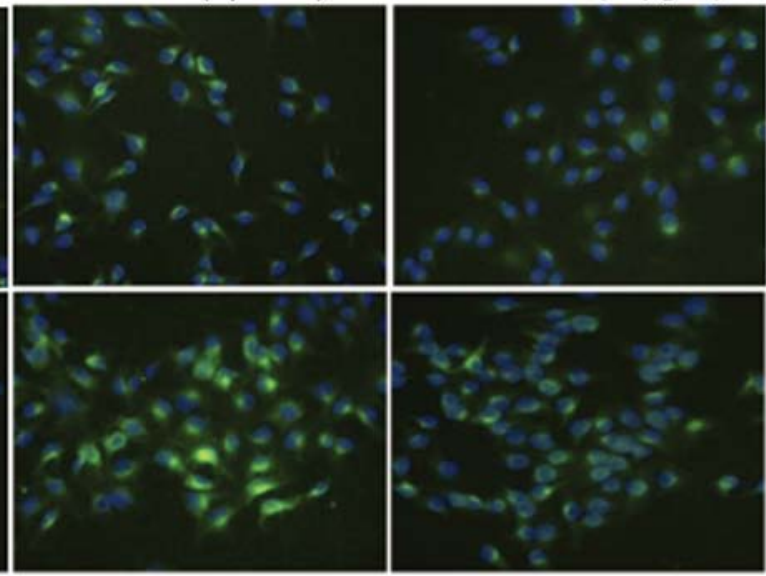

Figure 3. Effect of berberine microphthalmia-associated transcription factor (MITF) and tyrosinase levels of B16F10 melanoma cells. (A and B) B16F10 melanoma cells were co-treated with various concentrations of berberine $(0,0.01,0.1,1$ and $10 \mu \mathrm{g} / \mathrm{ml})$ and $\alpha$-melanocyte-stimulating hormone $(\alpha-\mathrm{MSH})(1 \mu \mathrm{M})$ for the indicated time points. The expression levels of MITF and tyrosinase were examined by (A) qPCR and (B) western blot analysis. Equal mRNA and protein was confirmed using GAPDH. (C) The expression of tyrosinase was confirmed by immunocytochemical (ICC) staining using specific anti-tyrosinase antibodies (green). Corresponding 4',6-diamidino-2-phenylindole (DAPI) nuclear staining (blue) and the merged images are shown. Each determination was made in triplicate, and the data shown are the mean $\pm \mathrm{SD}$. ${ }^{\dagger} \mathrm{P}<0.05$ vs. control, ${ }^{*} \mathrm{p}<0.05$ vs. $\alpha-\mathrm{MSH}$-stimulated (magnification, $\mathrm{x} 400$ ).

$\alpha$-MSH $(1 \mu \mathrm{M} / \mathrm{ml})+$ Berberine $(10 \mu \mathrm{g} / \mathrm{ml})$

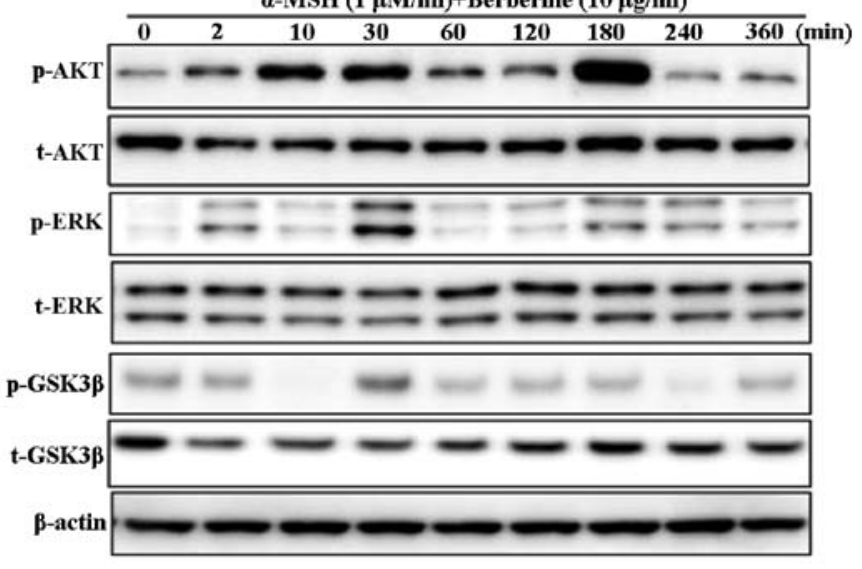

Figure 4. Effects of berberine on the melanogenesis-related signaling pathway in B16F10 melanoma cells. B16F10 melanoma cells were co-treated with berberine $(10 \mu \mathrm{g} / \mathrm{ml})$ and $\alpha$-melanocyte-stimulating hormone $(\alpha-\mathrm{MSH})(1 \mu \mathrm{M})$ for the indicated time points. The expression levels of the melanogenesis-related signaling pathway, which involves the phosphorylation of PI3K/AKT, ERK and GSK $3 \beta$, were examined by western blot analysis. Equal protein loadings were confirmed by AKT, ERK, GSK $3 \beta$ and $\beta$-actin expression.
Effects of berberine on the melanogenesis-related signaling pathway in B16F10 melanoma cells. The PI3K/AKT, ERK and GSK $3 \beta$ signaling pathways regulate melanogenesis. To elucidate the mechanism underlying the melanogenesis effect of berberine, B16F10 melanoma cells were exposed to $\alpha$-MSH $(1 \mu \mathrm{M} / \mathrm{ml})$ in the presence of berberine $(10 \mu \mathrm{g} / \mathrm{ml})$ for the indicated time points, and the protein extracts were then analyzed by western blot analysis. As shown in Fig. 4, berberine induced the phosphorylation of PI3K/AKT, ERK and GSK3 $\beta$ at early time points, i.e., $30 \mathrm{~min}$ to $3 \mathrm{~h}$ after exposure.

Effects of berberine on the melanogenesis-related signaling pathways by specific inhibitors in B16F10 melanoma cells. Since berberine activates phosphorylation of the PI3K/AKT, ERK, and GSK $3 \beta$ signaling pathways, we hypothesized that LY 294002, a selective inhibitor of PI3K; PD 98059, a selective inhibitor of ERK; and BIO, a selective inhibitor of GSK $3 \beta$, inhibits the suppressive effect of berberine on melanogenesis. B16F10 melanoma cells were treated with berberine $(10 \mu \mathrm{g} / \mathrm{ml})$ in the presence or absence of LY $294002(20 \mu \mathrm{M} / \mathrm{ml})$ or PD 98059 $(10 \mu \mathrm{M} / \mathrm{ml})$ or BIO $(1 \mu \mathrm{M} / \mathrm{ml})$ for 3 days, and the extracellular 


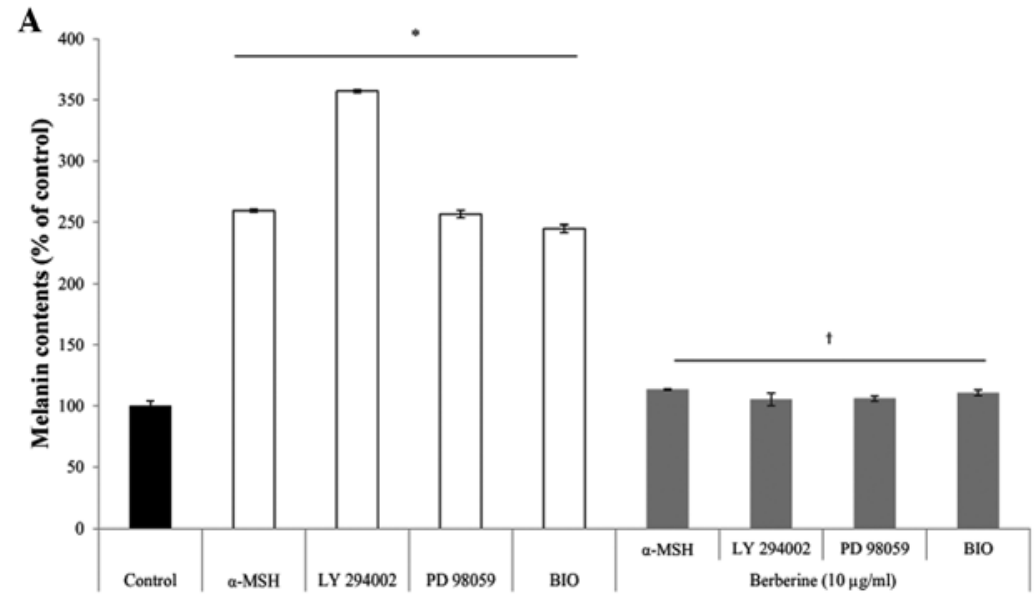

B

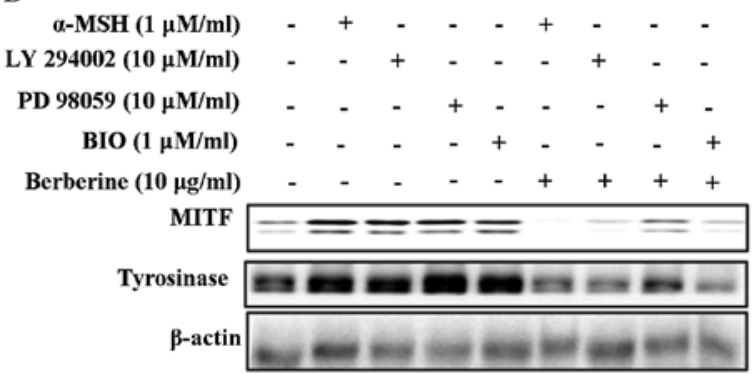

melanin release was measured. As shown in Fig. 5A, addition of the inhibitors increased the amount of melanin in the media. Berberine treatment inhibited this melanin release (Fig. 5A).

To further confirm the results shown in Fig. 5A, we examined the effect of the inhibitors on the expression level of melanogenesis-related proteins in B16F10 melanoma cells co-treated with berberine, $\alpha$-MSH or inhibitors (Fig. $5 \mathrm{~B}$ ). The data are consistent with Fig. 5A, showing that the phosphorylation of the PI3K/AKT, ERK, and GSK3 $\beta$ signaling pathway is associated with the reduction of melanogenesis by berberine. Thus, these results suggested that the reduction of melanogenesis by berberine is regulated by the specific inhibitors of anti-melanogenic signaling pathways, which involved the phosphorylation of the PI3K/AKT, ERK, and GSK $3 \beta$ signaling pathways.

\section{Discussion}

Berberine, an isoquinoline alkaloid, has a wide range of beneficial properties, including anti-bacterial, anti-inflammatory, anti-cancer and cholesterol-lowering effects (16-19). However, the exact mechanisms underlying these effects remain to be identified. Recently, studies on the effects of berberine found that it improved glucose and lipid metabolism disorders by increasing insulin sensitivity through the adjustment of adipokine secretions in preadipocytes in primary culture and in metabolic syndrome patients $(20,21)$. The anti-angiogenic activity of berberine via the downregulation of hypoxia-inducible factor-1, VEGF, and proinflammatory mediators was confirmed (22).
Figure 5. Effects of berberine on the melanogenesis-related signaling pathway in B16F10 melanoma cells. (A) B16F10 melanoma cells were pre-treated with LY $294002(10 \mu \mathrm{M} / \mathrm{ml}), \operatorname{PD} 98059(10 \mu \mathrm{M} / \mathrm{ml})$ or BIO $(1 \mu \mathrm{M} / \mathrm{ml})$ for $2 \mathrm{~h}$, or were treated with $\alpha$-melanocyte-stimulating hormone $(\alpha-\mathrm{MSH})(1 \mu \mathrm{M})$, and then treated with berberine $(10 \mu \mathrm{g} / \mathrm{ml})$ for $72 \mathrm{~h}$. The cellular melanin content was determined and expressed as a percentage relative to that of the control cells. (B) B16F10 melanoma cells were pre-treated with LY $294002(10 \mu \mathrm{M} / \mathrm{ml})$, PD $98059(10 \mu \mathrm{M} / \mathrm{ml})$ or BIO $(1 \mu \mathrm{M} / \mathrm{ml})$ for $2 \mathrm{~h}$, or were treated with $\alpha$-MSH $(1 \mu \mathrm{M})$, and then treated with berberine $(10 \mu \mathrm{g} / \mathrm{ml})$ for $30 \mathrm{~min}$. The expression levels of the melanogenesis-related signaling pathway, involving phosphorylation of PI3K/AKT, ERK and GSK $3 \beta$, were examined by western blot analysis. Equal protein loadings were confirmed by AKT, ERK, GSK $3 \beta$ and $\beta$-actin expression. Each determination was performed in triplicate, and the data shown are the mean \pm SD. ${ }^{*} \mathrm{P}<0.05$ vs. control, ${ }^{\dagger} \mathrm{p}<0.05$ vs. $\alpha-\mathrm{MSH}$ or inhibitors-stimulated.

In this study, we examined the expression of melanogenesis-related proteins including MITF and tyrosinase, and melanogenesis-regulating molecules including PI3K/AKT, ERK and GSK $3 \beta$ in order to elucidate the potential mechanisms by which berberine inhibits melanogenesis in B16F10 melanoma cells.

In particular, the PI3K/AKT and ERK signaling pathways are known as key mediators of $\alpha-\mathrm{MSH}$-induced melanogenesis (23-25). The GSK3 $\beta$ signaling pathway, which has been widely induced in the regulation of cell homeostasis due to its ability to phosphorylate a broad range of substrates, including glycogen synthase, the microtubule-associated protein $\tau$, and $\beta$-catenin, is also known to decrease the binding of MITF to the tyrosinase promoter (26).

This study has demonstrated that berberine decreases melanin synthesis and tyrosinase activity. Furthermore, we studied the effect of berberine on MITF and tyrosinase expression in B16F10 melanoma cells using RT-PCR and western blot analysis, and their expression was confirmed by ICC. Our data showed that expression of MITF and tyrosinase was attenuated by berberine (Fig. 3A-C).

Berberine inhibits the signaling pathways involved in $\alpha$-MSH-induced melanogenesis. Since activation of the PI3K/AKT, ERK, and GSK3 3 signaling pathways is associated with the inhibition of hyperpigmentation by decreasing MITF and tyrosinase activity (23-26), berberine may inhibit melanin synthesis by inducing the phosphorylation of PI3K/AKT and ERK. Using the specific inhibitors, LY 294002, PD 98059 and BIO, we found that berberine inhibited induced-melanin content, MITF and tyrosinase. 
In conclusion, berberine significantly inhibits melanogenesis in B16F10 melanoma cells. The berberine-induced phosphorylation of PI3K/AKT, ERK, and GSK3 $\beta$ may contribute to anti-melanogenic effects. The results that the beneficial effects of berberine on skin diseases caused by stress including UV light, are secondary to its inhibition of melanin synthesis. Further studies are required to assess the safety and efficacy of berberine for clinical use.

\section{Acknowledgements}

This study was carried out with the support of the 'Cooperative Research Program for Agricultural Science and Technology Development (project no. PJ0082312011)', Rural Development Administration, Republic of Korea.

\section{References}

1. Buscà R and Ballotti R: Cyclic AMP a key messenger in the regulation of skin pigmentation. Pigment Cell Res 13: 60-69, 2000.

2. Costin GE and Hearing VJ: Human skin pigmentation: melanocytes modulate skin color in response to stress. FASEB J 21: 976-994, 2007.

3. Yamaguchi Y, Brenner M and Hearing VJ: The regulation of skin pigmentation. J Biol Chem 282: 27557-27561, 2007.

4. Kubo I, Kinst-Hori I, Chaudhuri SK, Kubo Y, Sánchez Y and Ogura T: Flavonols from Heterotheca inuloides: tyrosinase inhibitory activity and structural criteria. Bioorg Med Chem 8: $1749-1755,2000$.

5. Cho JC, Rho HS, Baek HS, et al: Depigmenting activity of new kojic acid derivative obtained as a side product in the synthesis of cinnamate of kojic acid. Bioorg Med Chem Lett 22 2004-2007, 2012.

6. Ahn SM, Rho HS, Baek HS, et al: Inhibitory activity of novel kojic acid derivative containing trolox moiety on melanogenesis. Bioorg Med Chem Lett 21: 7466-7469, 2011.

7. Cabanes J, Chazarra S and Garcia-Carmona F: Kojic acid, a cosmetic skin whitening agent, is a slow-binding inhibitor of catecholase activity of tyrosinase. J Pharm Pharmacol 46 982-985, 1994

8. Maeda K and Fukuda M: Arbutin: mechanism of its depigmenting action in human melanocyte culture. J Pharmacol Exp Ther 276: 765-769, 1996.

9. Parvez S, Kang M, Chung HS, et al: Survey and mechanism of skin depigmenting and lightening agents. Phytother Res 20: 921-934, 2006

10. Nakajima M, Shinoda I, Fukuwatari Y and Hayasawa H: Arbutin increases the pigmentation of cultured human melanocytes through mechanisms other than the induction of tyrosinase activity. Pigment Cell Res 11: 12-17, 1998.
11. Wei CI, Huang TS, Fernando SY and Chung KT: Mutagenicity studies of kojic acid. Toxicol Lett 59: 213-220, 1991.

12. Giroir LE, Huff WE, Kubena LE, et al: Toxic effects of kojic acid in the diet of male broilers. Poult Sci 70: 499-503, 1991.

13. Parshad R, Sanford KK, Price FM, et al: Protective action of plant polyphenols on radiation-induced chromatid breaks in cultured human cells. Anticancer Res 18: 3263-3266, 1998.

14. Tu CX, Lin M, Lu SS, Qi XY, Zhang RX and Zhang YY: Curcumin inhibits melanogenesis in human melanocytes. Phytother Res 26: 174-179, 2012.

15. al-Sereiti MR, Abu-Amer KM and Sen P: Pharmacology of rosemary (Rosmarinus officinalis Linn.) and its therapeutic potentials. Indian J Exp Biol 37: 124-130, 1999.

16. Stermitz FR, Lorenz P, Tawara JN, Zenewicz LA and Lewis K: Synergy in a medicinal plant: antimicrobial action of berberine potentiated by 5'-methoxyhydnocarpin, a multidrug pump inhibitor. Proc Natl Acad Sci USA 97: 1433-1437, 2000.

17. Kuo CL, Chi CW and Liu TY: The anti-inflammatory potential of berberine in vitro and in vivo. Cancer Lett 203: 127-137, 2004.

18. Fukuda K, Hibiya Y, Mutoh M,Koshiji M, Akao S and Fujiwara H: Inhibition by berberine of cyclooxygenase-2 transcriptional activity in human colon cancer cells. J Ethnopharmacol 66: 227-233, 1999.

19. Kong W, Wei J, Abidi P, et al: Berberine is a novel cholesterollowering drug working through a unique mechanism distinct from statins. Nat Med 10: 1344-1351, 2004.

20. Yang J, Yin J, Gao H, Xu L, Wang Y and Li M: Berberine improves insulin sensitivity by inhibiting fat store and adjusting adipokines profile in human preadipocytes and metabolic syndrome patients. Evid Based Complement Alternat Med 2012: 363845, 2012.

21. Chen Y, Wang Y, Zhang J, Sun C and Lopez A: Berberine improves glucose homeostasis in streptozotocin-induced diabetic rats in association with multiple factors of insulin resistance. ISRN Endocrinol 2011: 519371, 2011.

22. Hamsa TP and Kuttan G: Antiangiogenic activity of berberine is mediated through the downregulation of hypoxia-inducible factor-1, VEGF, and proinflammatory mediators. Drug Chem Toxicol 35: 57-70, 2012

23. Santini E, Valjent E, Usiello A, et al: Critical involvement of cAMP/DARPP-32 and extracellular signal-regulated protein kinase signaling in L-DOPA-induced dyskinesia. J Neurosci 27: 6995-7005, 2007.

24. Wang JL, Chan RC, Cheng HH, et al: Short waves-induced enhancement of proliferation of human chondrocytes: involvement of extracellular signal-regulated map-kinase (erk). Clin Exp Pharmacol Physiol 34: 581-585, 2007.

25. Yoon HS, Lee SR, Ko HC, et al: Involvement of extracellular signal-regulated kinase in nobiletin-induced melanogenesis in murine B16/F10 melanoma cells. Biosci Biotechnol Biochem 71: 1781-1784, 2007.

26. Li H, Min YS, Park KC ansd Kim DS: Inhibition of melanogenesis by Xanthium strumarium L. Biosci Biotechnol Biochem 76: 767-771, 2012. 